\title{
An Experimental Study on the PV Systems' Contribution on Lowering the Demand Charge
}

\section{Mr. Jonathan Michael Newton, John Brown University}

Electrical/Computer Engineering student at John Brown University and a minor in Mathematics. Jonathan has a passion for computer programing, and the use of mathematics to create optimized solutions.

\section{Mr. Harrison Lee Hosteter, John Brown University}

Mechanical/Electrical/Computer Engineering student at John Brown University with a minor in Physics. Harrison was raised on a farm and developed a passion and respect for engineering and problem solving.

\section{Dr. Ted Song, John Brown University}

Dr. Ted Song joined the JBU engineering faculty in August of 2012. Dr. Song received his Ph.D. in Electrical and Computer Engineering from the University of Texas at Austin in 2012, and his doctoral dissertation is in the area of mathematical modeling of renewable energy sources (e.g. photovoltaic and wind) and energy storage system (e.g. lithium-ion battery). In addition, his current research interests include renewable energy technologies that can be effectively implemented in developing countries. 


\title{
An Experimental Study on the PV Systems' Contribution on Lowering the Demand Charge
}

\begin{abstract}
John Brown University (JBU) is charged for electricity usage based on two measurements: the peak power (i.e. demand) within the recent 12 months and the amount of energy used (i.e. $\mathrm{kWh}$ ). As the demand is a factor that currently contributes to the bill to the campus, it has been an interest of JBU to minimize the demand as much as possible to reduce the electricity cost.

In 2013 summer, a $10 \mathrm{~kW}$ photovoltaic (PV) system was installed on the roof of the engineering building on the university campus. While this installed PV system had a goal of reducing the peak power and the energy usage of the engineering building, the principal aim of the installation was to provide opportunities to engineering students to better understand how installed PV systems operate with the connection to the current grid and how return-on-investment (ROI) could be analyzed. In particular, as there are not many students who have experienced the demand charge that utilities charge to commercial customers, JBU has tried to use this system as a learning tool for students to realize the demand charge impact on the electricity cost.

From 2014 to 2016, a team of undergraduate engineering students has developed a monitoring system that could track the PV generation and the power usage of the building. A primary goal of this project was to determine the installed PV system's contribution to lowering the demand charge. Since this measurement of contribution could not be determined without the real-time collected data sets, the student team focused on gathering data sets from the PV system and building's power meter. With the collected data sets, how much the PV system contributed to lowering the cost of electricity usage and whether installed PV modules reduced the demand peak were analyzed.

Additionally, this paper discusses what has been learned through this student-led project and how hands-on activities on renewable energy sources could be used for students to understand the power system economics better.
\end{abstract}




\section{Introduction}

Where John Brown University (JBU) is located, commercial customers are charged for electricity usage in two different ways. Similar to residential customers, one part of the cost is based on the amount of energy used per month, measured in $\mathrm{kWh}$. The other part of the cost for commercial customers is a monthly charge based on the peak demand within the 12 months, measured in $\mathrm{kW}$.

In many cases, PV systems' contribution to lowering the cost of electricity usage is determined based on the amount of energy generated that replaced the equal amount of energy from the grid. While this is true for residential customers, this cost reduction model may not apply to commercial customers as they also are charged with the peak demand. Particularly, this is a new concept for most undergraduate engineering students as they have not been exposed to such a pricing model before.

JBU introduced this pricing model that includes the demand charge to students, and a team of students performed an experimental study that analyzes whether the installed PV system made a contribution to lowering the peak demand. In addition, the study was conducted by designing and developing a monitoring system to collect PV-generated and used power in the building in realtime.

Through this study, students were expected to achieve the following goals.

1. Understand how demand charge could impact the return-on-investment for commercial users.

2. Gain the ability to design and develop a monitoring system for collecting power generation/consumption data.

3. Understand the importance of the aligning renewable energy (RE) sources' power generation and peak power consumption.

\section{Background}

It is important to understand how the electricity bill is calculated monthly to determine the generated savings from the installed PV system. As mentioned, in the case of JBU, electricity is charged in two separate parts: energy usage $(\mathrm{kWh})$ and peak demand $(\mathrm{kW})$. The energy usage portion of the bill is determined by the total amount of energy consumed during that month with a set fee. While this charge continues to change year by year, the current (2016) cost for the engineering building on the campus is currently $\$ 0.06748$ per $\mathrm{kWh}$ for the first $10 \mathrm{MWh}$ and $\$ 0.06098$ per $\mathrm{kWh}$ when more than $10 \mathrm{MWh}$.

On the other hand, the demand portion of the bill is based on the peak power drawn within the recent 12-month period. The demand is calculated by averaging the instantaneous power value during 15-minute increments and is charged at a fixed rate per $\mathrm{kW}$ - the engineering building on campus currently pays $\$ 8.33$ per $\mathrm{kW}$ for the demand charge. Furthermore, the demand charge depends on a system called ratcheting. If the demand exceeds the previous demand, the cost 
ratchets and is determined by the new demand for that month. If the demand does not exceed again during that month, it is charged at $85 \%$ of the highest demand.

At JBU, the peak demands are most likely to occur at the beginning of each fall semester (typically in August) as this time is where new students move into the dorms. Often this is when the temperature is high, but most doors are open with the air conditioning turned on because of students' move into the dorms. For the months left in the year, the demand charge will be billed based on the $85 \%$ of peak demand, assuming that there is no new peak in the rest of the year.

Similar to other buildings on campus, the engineering building's peak demand occurs during the beginning of the fall semester as the air conditioning is heavily required as students start to use the facility. Since a $10 \mathrm{~kW}$ PV system was installed on the roof of the engineering building, the student team's goal was to verify the PV generation's contribution to the lowering the demand charge for this building's electricity bill.

\section{Methods and Results}

The priority to determining the savings in demand charge was to measure the power usage and PV system's power generation in real-time, and the student team developed a system that collects data sets to measure the power usage and generation values. This paper does not include the detailed information on the development of the monitoring system as it is out of the scope of the presented work, but the challenges include measuring in a synced time format and in real time, collecting the data sets from multiple systems, and converting them into a single and helpful form.

The data sets - from both the PV system and the power usage of the engineering building - were collected at 15-second increments over time to ensure accuracy in the peak detection. Also, for every 15 seconds, the output from both the PV system and the building power usage was measured simultaneously, which allowed for synced comparison of the output and demand. While the data sets for over six months were collected for the analysis, the peak analysis function was used in MATLAB to find the dates, time, and peak demand values only in July and August as peaks occur during these two months. Moreover, the algorithm for finding the desired peaks was based on a worst-case scenario. As mentioned, as the charge relies on the average over 15minute increments, a moving-average calculation was performed to find the worst case scenario 15-minute averages. A section of time would be shifted back and forth in 15-minute sections to determine the highest average for that period. Once the peaks were selected, they were plotted against the PV output for that date and time (Figure 1). 


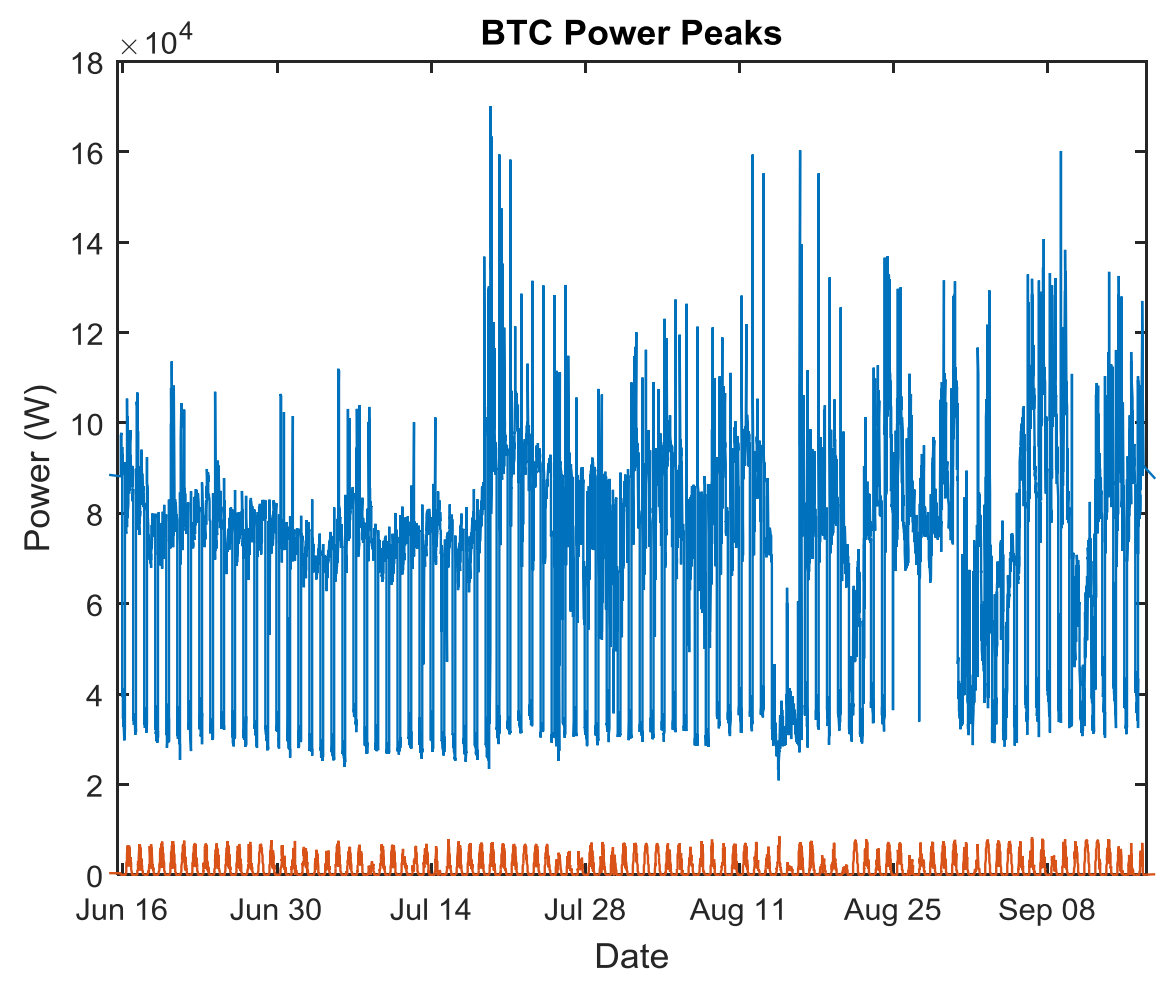

Figure 1. The 15-minute peak power averages for the engineering building and the associated PV system output in July and August 2016

As shown in Figure 1, the largest power peak occurred in July of 2016. Closer inspection of the peak indicates that it took place at 9:33 AM in the morning on July $19^{\text {th }}$ (Figure 2). As previously mentioned, the savings from the peak PV contribution can be calculated with the following equation.

Total Saving $(\$)=\mathrm{PV}$ power generated at the peak demand $(\mathrm{kW}) \times \operatorname{cost}(\$)$ per $\mathrm{kW}$

It was determined that the total savings for that peak (based only on the PV contribution to the peak) were $\$ 37.65$ (using the cost per $\mathrm{kW}$ of $\$ 8.33$ and the PV generated power $(4.52 \mathrm{~kW}$ ) at that particular time). Assuming that the peak would be the maximum for the next 12 months, the savings in demand charge for that year would be $\$ 32$ per month (i.e. $85 \%$ of the previous peak demand charge). Thus, the demand charge for the whole year is $\$ 389.65$ without considering cost savings from PV generated energy. Theoretically, if the peak demand occurred at the same time when the PV system generated power were at its peak, the savings in demand charge would be $\$ 862$ per year (i.e. $\$ 862=\$ 8.33 \times 10 \mathrm{~kW} \times 1$ month $+\$ 8.33 \times 10 \mathrm{~kW} \times 85 \% \times 11$ months). 


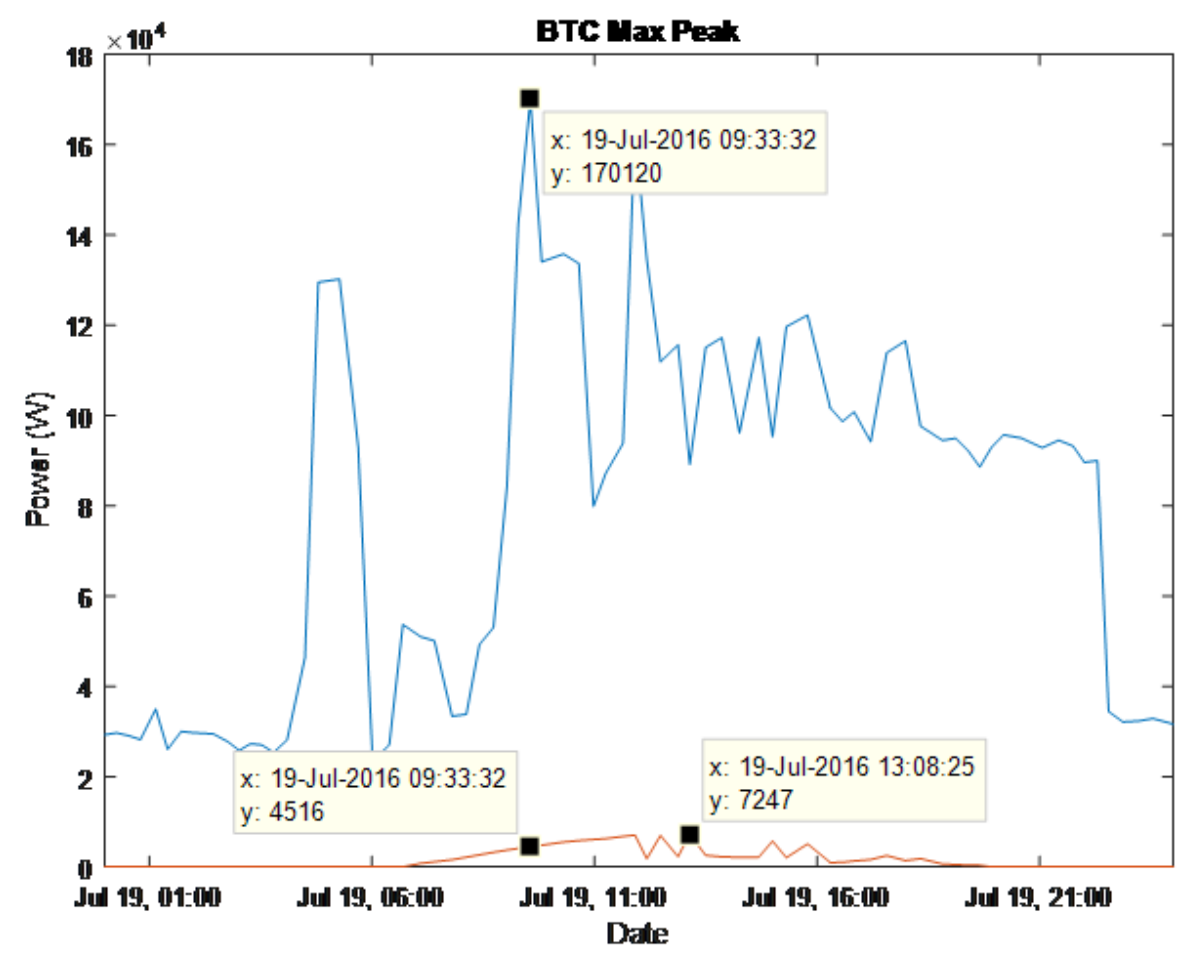

Figure 2. Measured peak demand for the engineering building on July 19, 2016

\section{Analysis}

The total cost of installing the $10 \mathrm{KW}$ PV system in 2013 summer was $\$ 39,335$. When $\$ 0.06748$ per $\mathrm{kWh}$ price from the local utility is used for calculation, this PV system provides in a saving of approximately $\$ 1,079$ per year and a payback period of 36.5 years as it generates about 16 MWh per year. By adding in the previously calculated savings from the demand charge, the savings become $\$ 1,468$ per year, dropping the payback period from 36.5 years to 26.8 years for the PV system.

It was previously stated that if the peak solar production occurred at the same time as the peak power demand, that there could be an additional savings of $\$ 472$ per year. If the total power produced remains the same, the new solar savings per year would be $\$ 1,941$ which would drop down the payback periods even further, from 26.8 years to 20.3 years for the PV system. This result shows that optimizing power demand with the PV generation could potentially reduce the payback period by a significant amount. TABLE I shows the summary of ROI calculation. It is also worth to mention that this result will vary based on the cost of electricity and the cost of PV generation on that site. 
TABLE I. Summary of ROI calculation for the $10 \mathrm{KW}$ PV system installed at JBU

\begin{tabular}{|c|c|c|c|}
\hline & $\begin{array}{c}\text { Savings in } \\
\text { demand charge }\end{array}$ & $\begin{array}{c}\text { Total savings } \\
\text { per year }\end{array}$ & Payback period \\
\hline $\begin{array}{c}\text { ROI calculation without considering } \\
\text { the demand charge savings }\end{array}$ & $\$ 0$ & $\$ 1,079$ & 36.5 years \\
\hline $\begin{array}{c}\text { ROI calculation with considering the } \\
\text { demand charge savings }\end{array}$ & $\$ 389$ & $\$ 1,468$ & 26.8 years \\
\hline $\begin{array}{c}\text { ROI calculation when the maximum } \\
\text { PV generation is hypothetically } \\
\text { matched with the peak demand }\end{array}$ & $\$ 862$ & $\$ 1,941$ & 20.3 years \\
\hline
\end{tabular}

As shown in TABLE I, there are missed opportunities for reducing the electricity cost by PV generation. Though the peak demand is capitalizing on some of the benefits, the peak power demand could theoretically be aligned with maximum PV generation for the maximum savings. For example, the demand of the building could be shifted by turning on the air conditioning (i.e. largest load in the building) at a particular time that could match the maximum PV generation.

\section{Conclusion}

A team of undergraduate engineering students investigated whether the installed PV system reduced the peak demand to minimize the electricity cost of the engineering building at JBU. While it was expected that the PV system would lessen the cost in demand charge, it was hard to measure its effectiveness before the monitoring system was installed to track the data sets from both the power consumption and PV generation in real-time. After the investigation, collected data sets showed that the current PV system saved around $\$ 389$ over a period of one year. It also was identified that the PV system was not contributing to lowering the peak demand as much as it could be. The student team concluded that the peak demand operating hours could be shifted to reduce the demand, even more, to make savings greater.

Additionally, students who participated in this project gained an experience of developing a power monitoring system and calculating the PV systems' effectiveness in reducing the cost with the consideration of the decreased demand charge. Students also identified that there is room for expansion in how PV systems can help to lower costs and some methods including passive alignment based on temperature and active alignment using electric motors. In particular, students were able to recognize the need for systems that can dynamically align the PV production and peak demand as combining the data monitoring with systems inside the buildings could allow for greater cost reduction through the alignments.

The presented experimental study also was used to teach students how the pricing model from the local utility could affect their system design and development. Students also provided feedback that using the collected data sets to calculate payback period was very helpful to gain insight on how renewable energy could have a stronger case for reducing the cost of electricity as it not only reduces the amount of energy consumption from the grid but also reduces the demand charge. Additionally, a likewise project could easily be used in other RE courses without the 
monitoring system as RE generation could be estimated using the available public data sets. This hands-on activity could well be used to introduce engineering students to the relationship between the electricity market and RE system designs. 